\title{
Synthesis and characterization of porous carbon derived from activated banana peels with hierarchical porosity for improved electrochemical performance
}

\author{
O. Fasakin ${ }^{a, b}$, J. K. Dangbegnon ${ }^{b}$, D. Y. Momodu ${ }^{b}$, M. J. Madito ${ }^{b}$, K.O. Oyedotun ${ }^{b}$, \\ M. A. Eleruja ${ }^{a}$ and N. Manyala*b \\ ${ }^{a}$ Department of Physics and Engineering Physics, Obafemi Awolowo University, Ile-Ife \\ 220005, Nigeria \\ ${ }^{b}$ Department of Physics, Institute of Applied Materials, SARCHI Chair in Carbon \\ Technology and Materials, University of Pretoria, Pretoria 0028, South Africa \\ *Corresponding author's email: Ncholu.Manyala@up.ac.za. \\ Tel.: +(27)12 420 3549; Fax: +(27)12 4202516
}

\begin{abstract}
Banana peels, a common fruit waste was adopted as a material precursor in this study to synthesize highly porous activated carbon from banana peels (ABP) which serves as an electrode material for a symmetric supercapacitor device. The activation was done using $\mathrm{KOH}$ pellets at different carbonization temperatures ranging from $750{ }^{\circ} \mathrm{C}$ to $950{ }^{\circ} \mathrm{C}$. The ABP sample obtained from the $900{ }^{\circ} \mathrm{C}$ carbonization temperature (ABP900) exhibited unique material properties such as hierarchical porous nano-architecture containing micropores, and mesopores with the highest specific surface area $\left(1362 \mathrm{~m}^{2} \mathrm{~g}^{-1}\right)$. Electrochemical performance investigation in different neutral aqueous electrolytes showed that the best response was obtained in $\mathrm{NaNO}_{3}$ for the ABP900 electrode. The symmetric device subsequently assembled using $1 \mathrm{M} \mathrm{NaNO}_{3}$ operated in a potential window of $1.8 \mathrm{~V}$, exhibited a specific capacitance of $165 \mathrm{~F} \mathrm{~g}^{-1}$ with a corresponding energy density of $18.6 \mathrm{~W} \mathrm{~h} \mathrm{~kg}^{-1}$ at $0.5 \mathrm{~A} \mathrm{~g}^{-1}$. A $100 \%$ capacitance retention and columbic efficiency were obtained after 10000 continuous charge-discharge cycles at $5 \mathrm{~A} \mathrm{~g}^{-1}$. Remarkably, after subjecting the symmetric device to a voltage holding test for 60 hours, the specific capacitance was observed to increase from $165 \mathrm{~F} \mathrm{~g}^{-1}$ to $328 \mathrm{~F} \mathrm{~g}^{-1}$ with a corresponding increased energy density to about $36.9 \mathrm{~W} \mathrm{~h} \mathrm{~kg}^{-1}$ at $0.5 \mathrm{~A} \mathrm{~g}^{-1}$, suggesting a $98 \%$ increase in device energy density from its initial value after voltage holding. Thus, the results reported showcase the ABP900 material as a potential nanostructured porous material useful in the design of high-performance electrodes for stable electrochemical capacitors.
\end{abstract}

Keywords: activated banana peel; electrodes; electrochemical capacitors; high energy density 


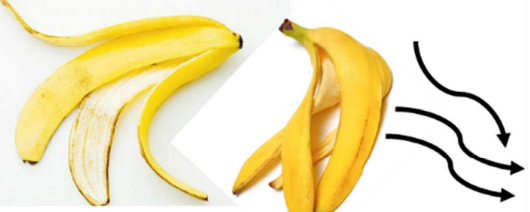

Raw waste material

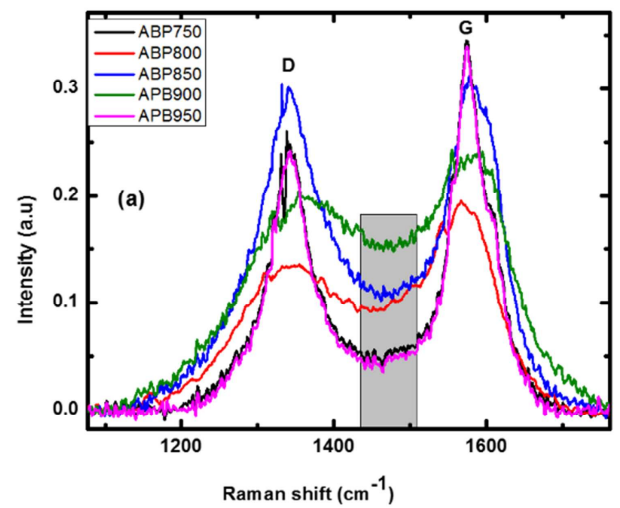

optimized

carbonization

@900 ㄷ

nanoporous product

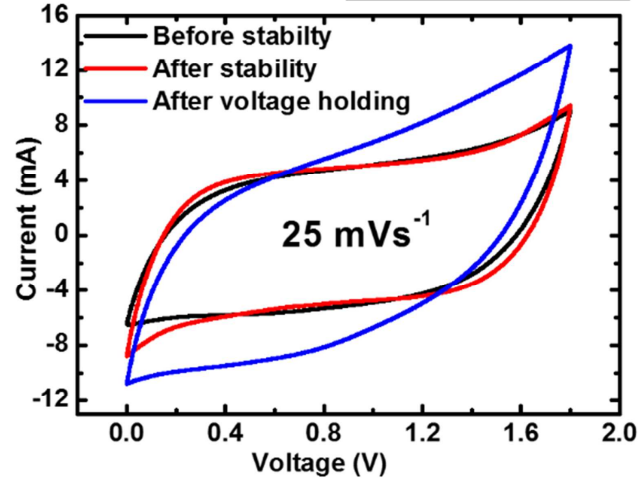




\section{Highlights}

- Conversion of banana peel fruit waste to highly porous activated carbon

- Optimum activation/carbonization parameters were obtained for this study

- Detailed electrochemical tests were done in different neutral aqueous electrolytes

- A stable symmetric device with good electrochemical performance was obtained 


\section{Introduction}

The global energy crisis experienced particularly in most developing parts of the world is of major concern today. The successful adoption of a renewable energy roadmap is dependent on the availability of cheaper means of storage of excess generated energy. In order to cut down the cost of storage units, an improvement on energy storage devices having a better stability, power and energy density with low post-maintenance cost is the key.

Supercapacitors (SCs) or Electrochemical Capacitors (ECs) are potential storage technologies compatible with most renewable energy sources. However, they proffer a good power output but a low energy density. Hence, the efforts to increase the energy density above the aforementioned value with excellent cycling ability is the way forward to having a better energy storage device. This device has a wide range of applications in hybrid electric vehicles, memory backup systems, uninterruptible power supply and other industrial equipment that relies on long-cycle times [1].

Generally, energy storage in SCs broadly involves two mechanisms namely; Non-faradic and faradaic reactions. Electrical Double Layer Capacitors (EDLCs) exhibits non-faradic reaction in which the electrostatic separation of electronic and ionic charges occurs between the electrode and electrolytes interface. This behaviour is commonly displayed by activated carbon materials and conducting polymers in organic electrolytes, [2] while the transition metal oxide materials exhibit faradaic reactions, that involved reduction-oxidation (Redox) reactions with nonrectangular voltammogram and non-linear charge-discharge curves, except in few materials such as $\mathrm{MnO}_{2}$ and $\mathrm{RuO}_{2}$ which also share similar characteristics of EDLC materials in neutral electrolytes and are widely referred to as pseudocapacitive materials [1]. 
For the development of high-performance energy storage carbon-based electrode materials, the challenge is how to achieve the desirable properties such as large specific surface area, high conductivity, efficiently hierarchical porosities in micro, meso- and macro-pores, 3D nanoarchitecture and high heteroatom doping [3]. Numerous studies have focused on using cheap biomass waste sources including banana fibres to produce high-quality valuable energy storage materials for SCs. For example, V. Subramanian et. al. [4] synthesized activated carbon from banana fibres with improved porosity using $\mathrm{KOH}$ and $\mathrm{ZnCl}_{2}$ as activating agents. The material was tested in $1 \mathrm{M} \mathrm{Na}_{2} \mathrm{SO}_{4}$ in a potential window of $1 \mathrm{~V}$ with a specific capacitance of $74 \mathrm{~F} \mathrm{~g}^{-1}$ obtained. More recently, rice husks were also used as precursor material in the production of high-performance porous carbons for SCs by X. He and co-workers [5]. In their study, they obtained a material with a specific surface area of $1442 \mathrm{~m}^{2} \mathrm{~g}^{-1}$ which was tested in $6 \mathrm{M} \mathrm{KOH}$. The material recorded up to $95.1 \%$ capacitance retention of its initial capacitance at a gravimetric current density of $2 \mathrm{~A} \mathrm{~g}^{-1}$. More comparison to our work with what has been reported in the literature can be found in table 3.

The present work involves the synthesis of a porous nanostructured carbon material obtained from the activation of banana peels with carbonization at different temperature ranging from $750{ }^{\circ} \mathrm{C}$ to $950^{\circ} \mathrm{C}$. The reason for using different carbonization temperatures was to determine the optimum synthesis conditions required to obtain a high-performance carbon material suitable for device application. The as-synthesized porous carbon was tested in sulphate and nitrate aqueous electrolytes $\left(1 \mathrm{M} \mathrm{Na}_{2} \mathrm{SO}_{4}, 1 \mathrm{M} \mathrm{Li} \mathrm{LO}_{4}\right.$ and $1 \mathrm{M} \mathrm{NaNO}$ ) in a three-electrode measurement configuration. The nitrate-based electrolytes displayed the best electrochemical performance, which was related to the small hydrated radius of the nitrate ion. The choice of using neutral electrolytes with activated carbon-based materials was due to its ability to attain 
higher potential as compared to alkaline and acidic aqueous electrolytes [6]. Also, these electrolytes are cheap, non-corrosive and permit the adoption of diverse current collectors, which make the capacitor assembling much easier and cheaper. Additionally, they are electrochemically stable and environmentally friendly [7]. Most importantly, the improvement in the performance of the cell after voltage holding test was striking when compared to earlier reports $[8,9]$ on biomass-derived activated carbon materials. These results provide a pathway to analyzing some new phenomena which occur at the electrolyte-electrode interface of activated carbon materials.

\section{Experimental}

\subsection{Synthesis of activated carbon from banana peel (ABP)}

The banana peels (BP) waste collected from a popular dumping site (Olu ere) at lle-ife in Nigeria were used as the raw material precursor. The peels were repeatedly washed with acetone and distilled water to remove all the dirt and dried at $60{ }^{\circ} \mathrm{C}$ for 24 hours. The cleaned and dried BP was sliced into smaller pieces and $10 \mathrm{~g}$ of the raw material was soaked in $100 \mathrm{ml}$ of distilled water containing $10 \mathrm{ml}$ of $0.5 \mathrm{M}$ sulphuric acid, transferred into a $120 \mathrm{ml}$ stainless steel autoclave unit which was then sealed and heated up to $160^{\circ} \mathrm{C}$ for 12 hours. The resulting black product was allowed to naturally cool down to room temperature and was filtered and dried at $80^{\circ} \mathrm{C}$ for 48 hours. The dried product was mixed with potassium hydroxide pellet in a mass of ratio 1:1 using an agate mortar before being carefully placed in a horizontal tube furnace for carbonization. The carbonization process was done at a ramp rate of $5^{\circ} \mathrm{C} \min ^{-1}$ to $750{ }^{\circ} \mathrm{C}$ under continuous argon gas flow for $1 \mathrm{~h}$. The same procedure was repeated at different temperatures $\left(800{ }^{\circ} \mathrm{C}, 850{ }^{\circ} \mathrm{C}, 900{ }^{\circ} \mathrm{C}\right.$ and $\left.950{ }^{\circ} \mathrm{C}\right)$. The carbonized materials were washed with $3 \mathrm{M}$ 
hydrochloric acid and distilled water until a neutral $\mathrm{pH}$ value was reached. The final product was dried at $60^{\circ} \mathrm{C}$ for 24 hours in an electric oven. The samples were labeled as APBX where $\mathrm{X}$ represents the carbonization temperature.

\subsection{Physico-chemical characterization}

The detailed morphology and structure of the activated carbon were studied using Scanning electron microscopy (Zeiss Ultra plus 55 field emission scanning electron microscope, FESEM) and transmission electron microscope (JEOL JEM-2100F). X-ray powder diffraction (XRD) was used to investigate the crystallinity of the samples. The diffraction patterns were obtained from an XPERT-PRO Diffractomer (PANalytical, Netherland) coupled with a cobalt target $(\lambda=$

1.7890Å). Raman analysis of the samples was recorded using a WiTec-alpha 300R+ confocal Raman spectrometer WiTec $\mathrm{GmbH}$ ) with the $532 \mathrm{~nm}$ laser power of $1.5 \mathrm{~mW}$ through a numerical aperture of 0.9 and $100 x$ magnification. The material textural properties were obtained using the Brunauer-Emmett-Teller (BET) technique from a Micrometrics Tristar II 3020 (version 2.00) Analyzer at $-196^{\circ} \mathrm{C}$. The pore size distribution plots were obtained from the desorption branch of the Barrett-Joyner-Halenda (BJH) plots.

\subsection{Electrochemical characterization}

Electrochemical analysis of the ABP samples was done on a VMP300 Bio-logic instrument. The electrodes were prepared by mixing the active material (ABPX), polyvinylidene fluoride (PVDF) binder and acetylene carbon black in a mass ratio of 80:10:10. Then, few drops of N-methyl-2pyrrolidone (NMP) were added to make a slurry. The slurry was homogeneously coated on nickel foam (NF) current collector and dried at $60{ }^{\circ} \mathrm{C}$ for 24 hours. Three electrode measurement tests were initially performed to understand the charge storage property of the 
electrode material in three neutral electrolytes $\left.\left(1 \mathrm{M} \mathrm{Li}_{2} \mathrm{SO}_{4}, 1 \mathrm{M} \mathrm{Na} \mathrm{SO}_{4}, 1 \mathrm{M} \mathrm{NaNO}\right)_{3}\right)$ using a $\mathrm{Ag} / \mathrm{AgCl}$ reference electrode and glassy carbon counter electrode.

A symmetric electrochemical capacitor device was subsequently assembled in a Swagelok with filter paper as the separator and $1 \mathrm{M} \mathrm{NaNO}_{3}$ as the operating electrolyte. The total mass per unit area of active material in the full device was calculated as $\sim 4.2 \mathrm{mg} \mathrm{cm}^{-3}$ while a specific mass of $\sim 3.0 \mathrm{mg} \mathrm{cm}{ }^{-2}$ was maintained in three-electrode measurements. The cyclic voltammetry (CV) and chronopotentiometry (CP) measurements were investigated at different scan rates and current densities, respectively. The electrochemical impedance spectroscopy (EIS) tests were run in a frequency range of $100 \mathrm{KHz}$ to $0.01 \mathrm{~Hz}$.

\subsection{Theory/ calculations}

The specific capacitance $\left(C_{\mathrm{sp}}\right)$ of a single electrode (anode and cathode) was determined using the following equations (1) and (2):

$$
\begin{aligned}
& C_{T}=\frac{I \Delta t}{\Delta V} \\
& C_{s p}=\frac{4 I \Delta t}{\Delta V M_{T}}
\end{aligned}
$$

The basic expression for energy density $\left(E_{\mathrm{d}}\right)$ in the unit $\mathrm{J} \mathrm{g}^{-1}$ and the corresponding power density $\left(P_{d}\right)$ of the complete device were calculated from equations (3) and (4):

$E_{d}=\frac{1}{2} C_{s p}(\Delta V)^{2}$

To convert the units to $\mathrm{W} \mathrm{h} \mathrm{g}^{-1}$ the above expression is divided by a factor of 3600 , and to further convert the units to $\mathrm{W} \mathrm{h} \mathrm{kg}^{-1}$ the expression is multiplied by a factor of 1000 , as shown 
in the following equation and the factor of $1 / 4$ is to correct for the use of the specific capacitance of the cell not that of a single electrode as is the case for equation 2:

$E_{d}=\frac{1}{2} C_{s p}(\Delta V)^{2}=\frac{1000 \times \mathrm{C}(\Delta \mathrm{V})^{2}}{2 \times 4 \times 3600}$

Therefore,

$E_{d}\left(\mathrm{wh} \mathrm{kg} g^{-1}\right)=\frac{\mathrm{C} . \Delta V^{2}}{28.8}$

$P_{d}\left(W \mathrm{~kg}^{-1}\right)=3600 \cdot \frac{E_{d}}{\Delta \mathrm{t}}$

The coulombic efficiency $(\varepsilon)$ were deduced from the charge and discharge curves using the equation (5)

$\varepsilon=\frac{\Delta t_{\text {discharge }}}{\Delta t_{\text {charge }}} 100 \%$

where $M_{T}$ is the total electrode mass, $C_{T}$ is the total capacitance of the electrode, $l$ is the current applied, $\Delta t$ is the discharge or charge duration, and $\Delta V$ is the device potential window.

\section{Results and discussion}

Scanning Electron Microscopy (SEM) and Transmission Electron Microscopy (TEM) techniques were used to investigate the surface analysis of the as-synthesized materials. Fig. 1(a-e) shows the SEM micrographs of the ABPs synthesized at different temperatures in the range of 750 $950^{\circ} \mathrm{C}$. The micrographs showed porous cavities on the surface of the material, which occurred as a result of the interaction of the activating agent $(\mathrm{KOH})$ with the $\mathrm{BP}$ raw material during and after the carbonization process. There is an evolution from a granular structure at low temperature $\left(750-850{ }^{\circ} \mathrm{C}\right)$ to a porous $3 \mathrm{D}$ structure at $900{ }^{\circ} \mathrm{C}$ and back to material with a 

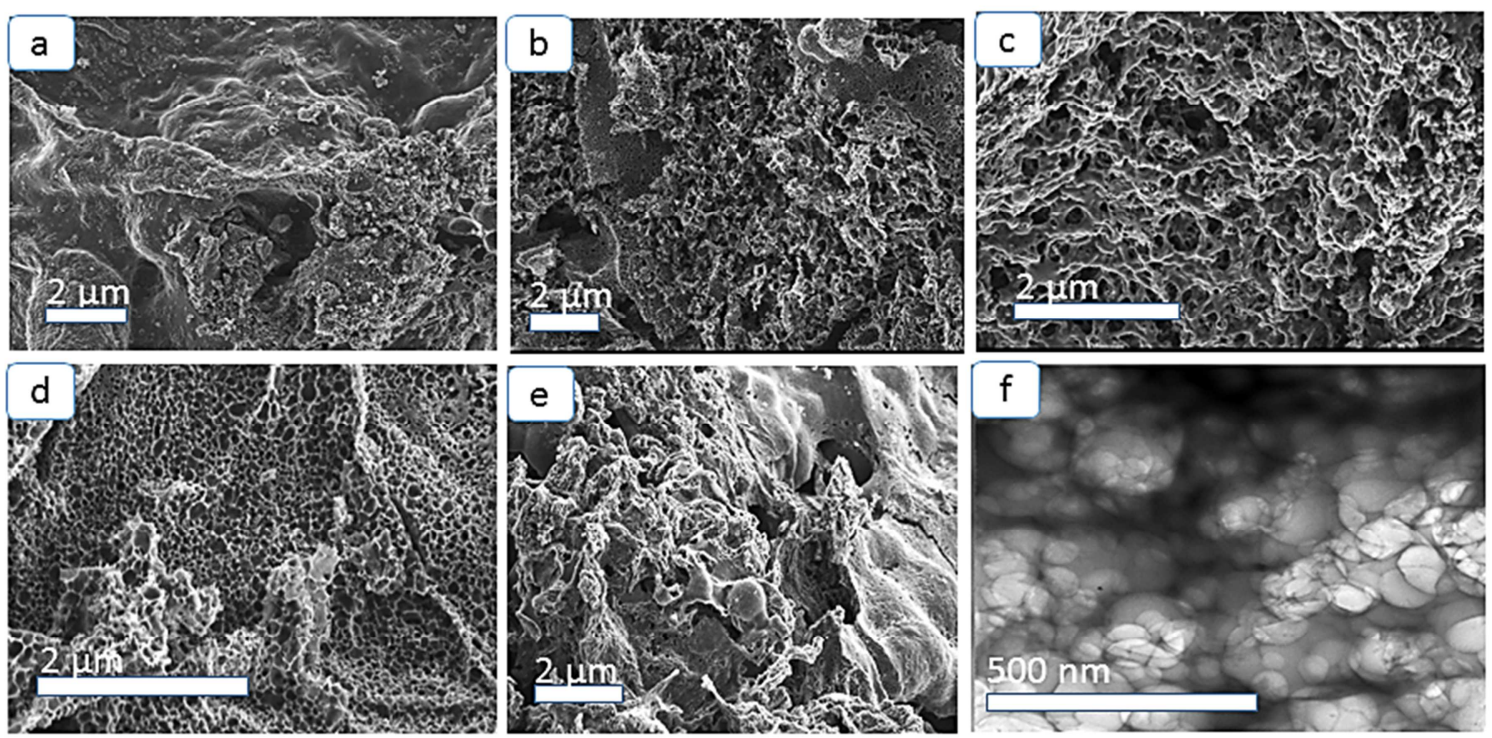

Fig. 1: (a) SEM images of activated banana peel samples (ABPs) carbonized at different temperatures: (a) ABP750, (b) ABP800, (c) ABP850, (d) ABP900, (e) ABP950 and (f) TEM image of $\mathrm{ABP}$ at $900{ }^{\circ} \mathrm{C}(\mathrm{ABP} 900)$ 
mixture of bigger grains and large pores at $950^{\circ} \mathrm{C}$. The uniform 3D porous structure obtained at $900^{\circ} \mathrm{C}$ seems to suggest that the best carbonization temperature is indeed $900^{\circ} \mathrm{C}$. The TEM analysis also gave a detailed morphology of the prepared carbon material (ABP900) at higher magnification as shown in Fig. 1(f) which showed that the carbon material possessed uniform interconnected 3D network which is favorable for supercapacitor application.

The structural analysis of carbonaceous materials was studied by XRD and Raman. In Fig. 2, the XRD results were matched to graphite ICSD card 31170 with space-group of P63mc. At lower activation temperatures $\left(750\right.$ to $850^{\circ} \mathrm{C}$ ) the samples show diffraction peaks which do not match the ICSD card. At high carbonization temperatures $\left(900\right.$ to $\left.950^{\circ} \mathrm{C}\right)$ the diffraction peaks that are observed at lower carbonization temperatures $\left(750\right.$ to $850^{\circ} \mathrm{C}$ ) disappear, and the samples show rather broadened (002) and (012) peaks at about $30.5^{\circ}$ and $52.0^{\circ}$ which suggest a high disorder in the samples, translating to higher degree of amorphous carbon state in all samples.

Fig. 3 shows the deconvoluted Raman spectra of ABPX ( $X=750,800,850,900$ and 950) synthesized at different temperatures. The peaks in Fig. 3(a) were deconvoluted in four different combinations of peaks to analyze the vibrational modes of the produced carbon materials in details using a curve fitting with Lorentzian distribution, as shown in Fig. 3(b-f). The G-band at approx. $1587 \mathrm{~cm}^{-1}$ wavenumber corresponds to an ideal graphitic lattice vibrational mode with the $E_{2 G}$ symmetry and the D-band which appears at about $1340 \mathrm{~cm}^{-1}$ corresponds to graphitic lattice vibration mode with $A_{1 g}$ symmetry. It is also linked to the characteristics of defect or disorder in the carbon material [6]. The intensity of the G-band to the intensity of the D-band $\left(I_{D} / I_{G}\right)$ ratio increases from 0.8 to 1.5 as the carbonization temperature increased from 


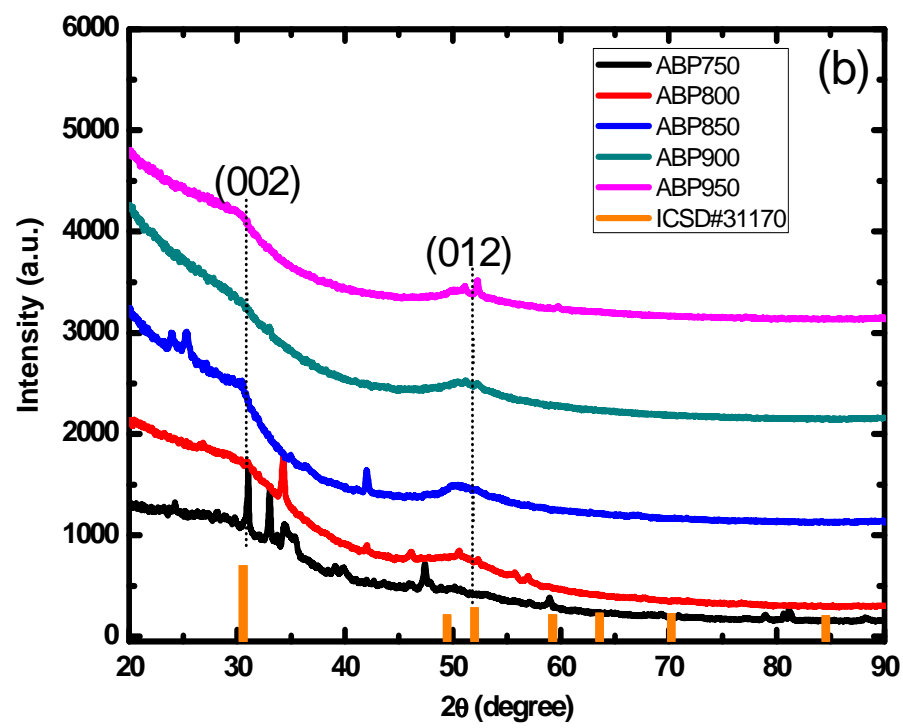

Fig. 2. X-ray diffraction spectra of activated banana peel samples (ABPs) at different carbonization temperature ranging from 750 to $950^{\circ} \mathrm{C}$, i.e. ABP750, ABP800, ABP850, ABP900 and ABP950 

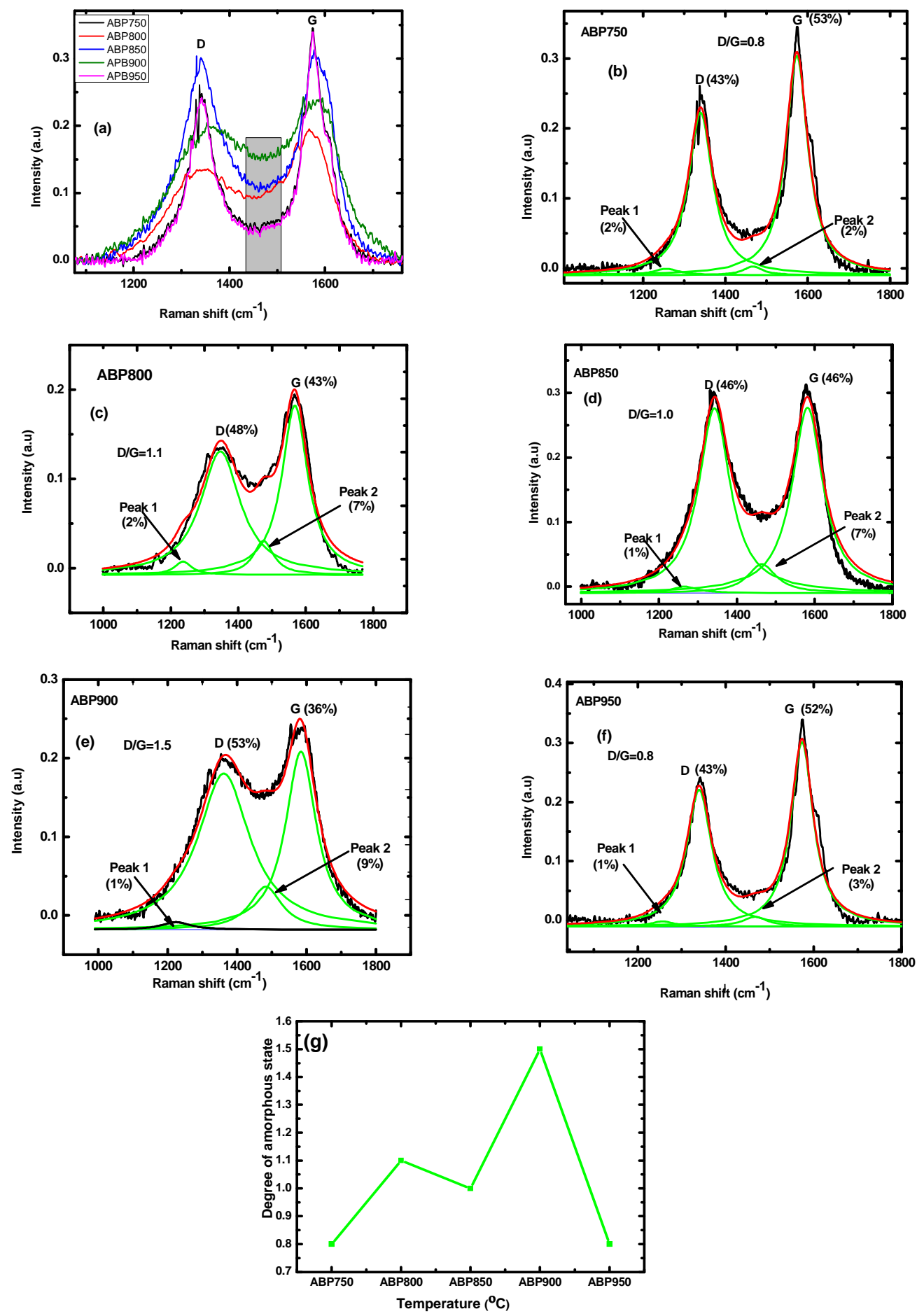

Fig. 3. (a) Raman spectra and their detailed deconvolutions of activated banana peel samples (ABPs) at different carbonization temperature ranging from 750 to $950^{\circ} \mathrm{C}$. (b - f) Deconvolution of Raman spectra of activated banana peel samples at different temperatures and (g) Degree of amorphous state against temperature from Raman deconvolutions. 
750 to $900{ }^{\circ} \mathrm{C}$ which indicates a decrease in the degree of graphitization for carbonization temperature up to $900^{\circ} \mathrm{C}$.

Thereafter, it decreases back to 0.8 at a temperature of $950{ }^{\circ} \mathrm{C}$ suggesting that a high temperature of $950{ }^{\circ} \mathrm{C}$ recrystallizes the graphitic structure of the sample. In the deconvoluted spectrum, peak 1 band is related to lattice vibrations corresponding to $\mathrm{sp}^{2}$-sp $\mathrm{sp}^{3}$ bonds $[10,11]$ and peak 2 band is known to originate from the distribution of amorphous carbon in interstitial sites in the disturbed graphitic lattice [12].

Briefly, the Raman spectra analyses suggest that the ABP900 sample consists of a significant fraction of interstitial amorphous carbon in the lattice structure. This is clearly shown in Fig. $3 \mathrm{~g}$. Furthermore, the degree of graphitization seems to increase with the appearance of the granular structure shown in Fig.1, suggesting that the compact structure of carbon tends to be more crystalline.

The surface texture of the ABP materials was analyzed by $\mathrm{N}_{2}$ adsorption/desorption analysis using the BET method and the results are shown in Fig. 4. It can be deduced from Fig. 4(a) that when the temperature was increased above $750{ }^{\circ} \mathrm{C}$, the shapes of the isotherm exhibited a type-II behaviour with an H4-type hysteresis indicating complex material containing both micropores and mesopores [6]. The micropores directly account for the charge storage and ion adsorption while mesopores create channels for ions during their transport from the neutral electrolyte bulk to the electrode/electrolyte interface. In Fig. 4(b), the specific surface area (SSA) and micropores volume were observed to increase as the carbonization temperature was increased up to $900^{\circ} \mathrm{C}$. A further increase in the temperature shows an abrupt decrease in SSA, as recorded at $950^{\circ} \mathrm{C}$. 

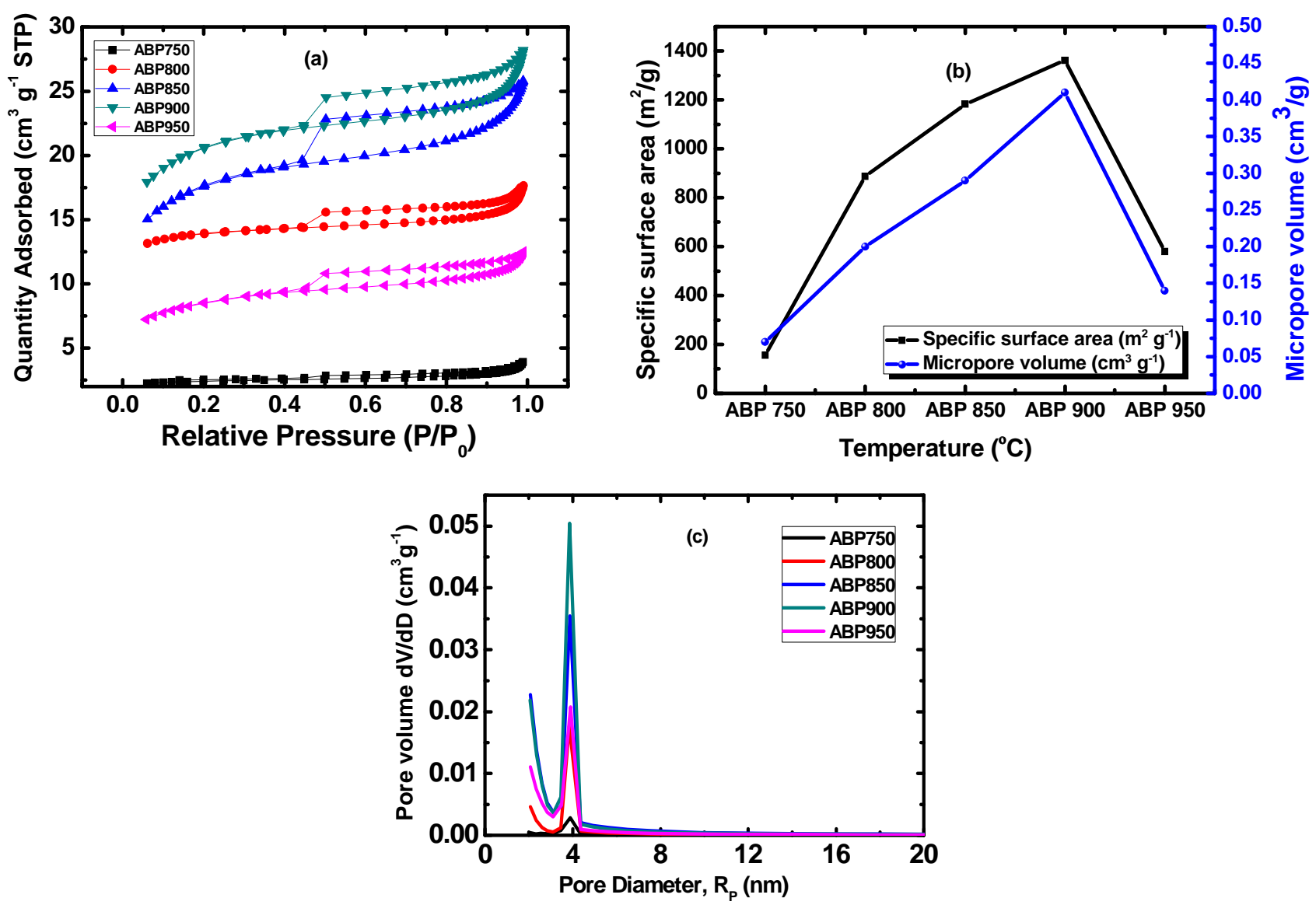

Fig. 4. (a) N2 absorption/desorption isotherms for all carbonized samples; (b) The plot of specific surface area and micropore volume as a function of temperature and (c) pore size distribution plot for the activated samples at different carbonization temperature ranging from 750 to $950{ }^{\circ} \mathrm{C}$ 
Once again, the granular texture seems to influence the SSA and micropore volume in these samples. Fig. 4(c) displays the PSD plot for all carbonized samples at different temperatures ranging from $750-950{ }^{\circ} \mathrm{C}$. The pore size distribution (PSD) was determined using the BarrettJoyner-Halenda $(\mathrm{BJH})$ analysis within the range $2-20 \mathrm{~nm}$ range. All the ABPX samples exhibited the presence of mesoporous and the shape of the curve below $2 \mathrm{~nm}$ also suggests the presence of micropores. The higher surface area and higher micropore volume are beneficial in charge storage by providing high adsorbate accessibility [13].

Since ABP900 exhibits the best properties for storage, based on the results obtained from the initial structural, textural and morphological characterization results, electrochemical measurements for ABP900 was performed in three neutral aqueous electrolytes $\left(1 \mathrm{M} \mathrm{Na}_{2} \mathrm{SO}_{4}\right.$, $1 \mathrm{M} \mathrm{Li}_{2} \mathrm{SO}_{4}$ and $1 \mathrm{M} \mathrm{NaNO}_{3}$ ) in a three-electrode measurement configuration and the results obtained are presented in Fig. 5. Fig. 5(a) shows the cyclic voltammetry of the material in both positive and negative potential windows of $0-0.9 \mathrm{~V}$ and $-0.9-0 \mathrm{~V}$, respectively at a scan rate of $25 \mathrm{mV} \mathrm{s}^{-1}$.

The CV curves exhibit quasi-rectangular shape which is typical for electric double layer capacitor (EDLC) behaviour. Furthermore, the current response in $\mathrm{NaNO}_{3}$ seems to be the highest among all electrolytes. The associated specific capacitance values calculated from the charge-discharge plot of chronopotentiometry tests at the positive potential are presented in Fig. 5(b). It confirms that the aqueous $\mathrm{NaNO}_{3}$ electrolyte gave the best material response in terms of charge storage capability. This could be linked to the size of the solvated $\mathrm{Na}^{+}(\mathrm{aq})$ and $\mathrm{NO}_{3}^{-}(\mathrm{aq})$ ions. In other terms, the electrochemical performance of the aqueous electrolytes could be better explained in terms of the ionic radii, the radius of the ionic hydrated sphere, ionic conductivity and mobility of the electrolytes. These properties are summarized in Table 1 . The 

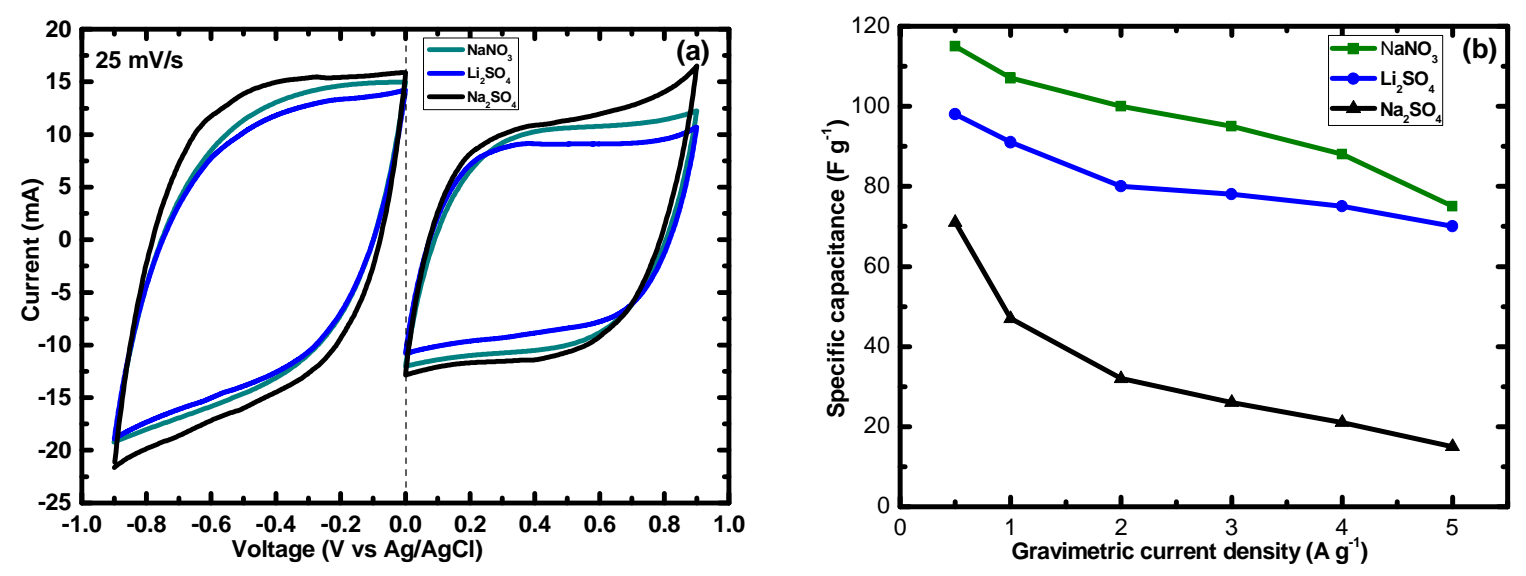

Fig. 5. (a) Cyclic voltammetry (CV) curves of the ABP900 sample displaying the EDLC response at the positive and negative potential (b) associated specific capacitances as a function of gravimetric current density $\left(0.5-5.0 \mathrm{~A} \mathrm{~g}^{-1}\right)$ at the positive operating potential in a three-electrode test configuration using different neutral electrolytes 
Table 1: The sizes of bare and hydrated ions, and ionic conductivity values

\begin{tabular}{lccc}
\hline Ion & Bare ion size $(\AA)$ & Hydrated ion size $(\AA)$ & lonic conductivity $\left(\mathrm{S} \mathrm{cm}^{2} \mathrm{~mol}^{-1}\right)$ \\
\hline $\mathrm{Li}^{+}$ & $0.60[18]$ & $3.82[17,18]$ & $38.69[16]$ \\
$\mathrm{Na}^{+}$ & $0.95[18]$ & $3.58[17,18]$ & $50.11[16]$ \\
$\mathrm{NO}_{3}{ }^{-}$ & $2.64[18]$ & $3.35[18]$ & $71.42[16]$ \\
$\mathrm{SO}_{4}{ }^{2-}$ & $2.90[18]$ & $3.79[18]$ & $160[16]$ \\
\hline
\end{tabular}


hydrated ion size of $\mathrm{Na}^{+}$is $3.59 \AA$ which is smaller than that of $\mathrm{Li}^{+}$is $3.81 \AA$ with higher ionic conductivity values of $50.11 \mathrm{~S} \mathrm{~cm}^{2} \mathrm{~mol}^{-1}$ than for $\mathrm{Li}^{+}\left(38.69 \mathrm{~S} \mathrm{~cm}^{2} \mathrm{~mol}^{-1}\right)$. Thus, $\mathrm{Na}^{+}$can move faster than $\mathrm{Li}^{+}$, towards the negative electrode with less resistance, storing more charge $[7,14$, 15]. Similarly, on the positive electrode, accumulation of $\mathrm{NO}_{3}{ }^{-}$ions might also be higher to that of $\mathrm{SO}_{4}{ }^{2-}$, owing to the smaller radius of the hydrated $\mathrm{NO}_{3}{ }^{-}$. Although, hydrated $\mathrm{SO}_{4}{ }^{2-}$ has higher ionic conductivity, it can encounter higher resistance due to its size, slowing the charging process.

The ABP900 carbon electrode in all aqueous electrolytes also exhibited good rate capability. For the $1 \mathrm{M} \mathrm{NaNO}_{3}$ electrolyte, the specific capacitance $\left(C_{\mathrm{S}}\right)$ was calculated as $115 \mathrm{~F} \mathrm{~g}^{-1}$ at a gravimetric current density of $0.5 \mathrm{~A} \mathrm{~g}^{-1}$ and was still retained at $75 \mathrm{~F} \mathrm{~g}^{-1}$ at $5 \mathrm{~A} \mathrm{~g}^{-1}$, representing $65 \%$ of its value at $0.5 \mathrm{~A} \mathrm{~g}^{-1}$. Fig. $6(a-b)$ presents the $\mathrm{CV}$ curves at different scan rates of 5-100 $\mathrm{mV} \mathrm{s}^{-1}$ for the positive and negative potential windows. The rectangular CV curves still remain at high scan rate, implying fast ions transfer.

The charge-discharge curves in both positive and negative potential windows also remain triangular for all gravimetric currents (Fig. S1 (a-b)), confirming the fast ions transfer process. This further corroborated the claim on the possibility of the carbon electrode to work in both positive and negative potentials windows of $0.9 \mathrm{~V}$ each in three-electrode measurements. The associated values of specific capacitance are shown in Fig. 6 (c). The values calculated are higher in the negative potential than in the positive potential, suggesting better charge separation in the negative potential windows. 

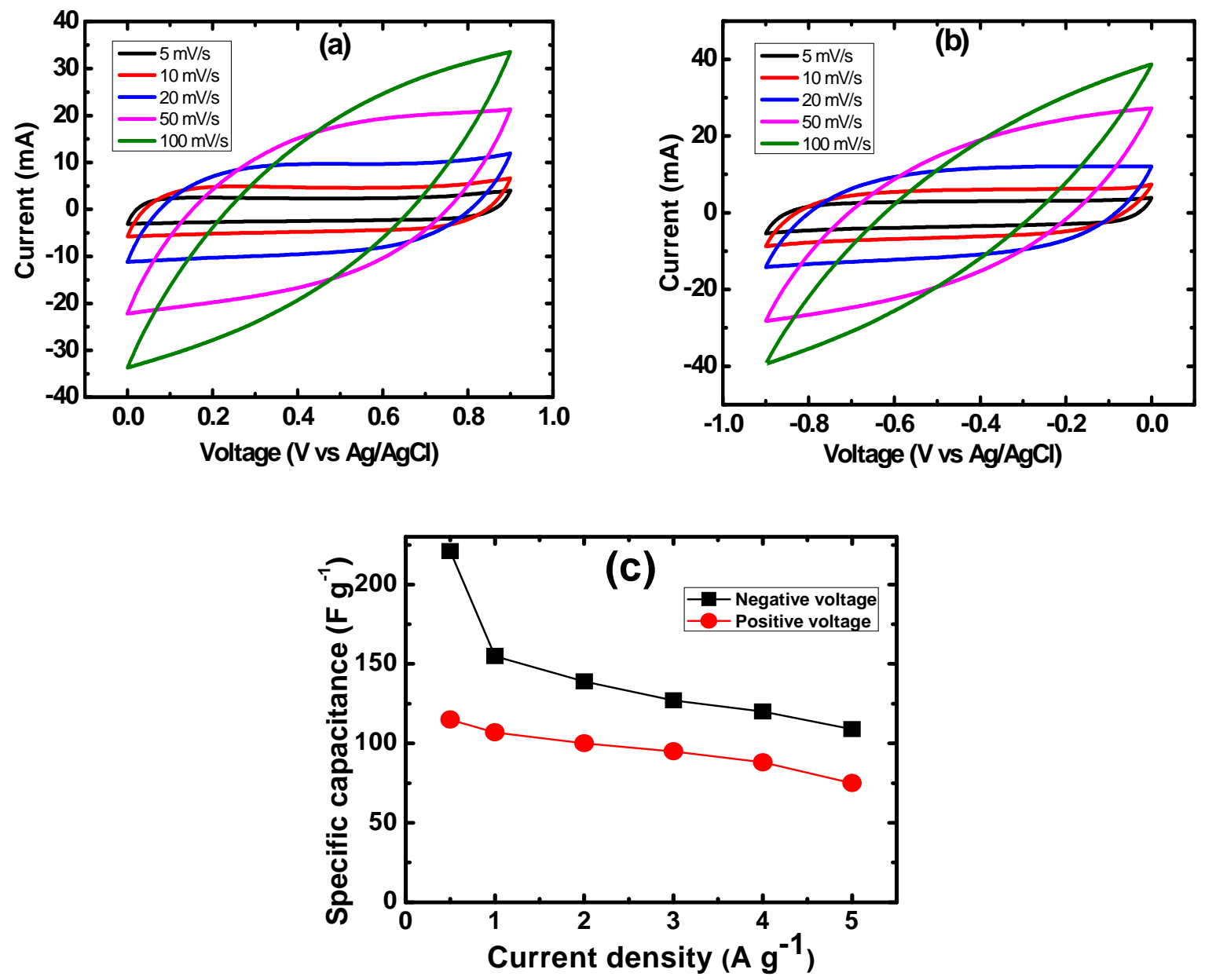

Fig. 6. (a, b) CV plots of the activated banana peel sample (ABP900) at different scan rates in positive and negative potential windows, respectively and (c) associated specific capacitance as a function of current density for both positive and negative voltages in three-electrode measurements 
Moreover, for an increase of the gravimetric current from 1 to $5 \mathrm{~A} \mathrm{~g}^{-1}, 70 \%$ capacitance retention was obtained for this electrode in both potentials. Hence, the material exhibits an excellent rate capability regardless of its polarity.

Based on the results obtained from the half-cell measurements, a full symmetric device was then assembled to tap into its ability to function in both negative and positive operating potential. Fig. 7(a-b) shows the two-electrode CV and CP plots at varying scan rates and gravimetric current densities.

Results from the CV and CP analysis exhibited rectangular and triangular shapes, respectively, indicating EDLC response in a device potential range of $1.8 \mathrm{~V}$. The specific capacitance of the cell at $0.5 \mathrm{~A} \mathrm{~g}^{-1}$ was calculated as $165 \mathrm{~F} \mathrm{~g}^{-1}$. This value was still $135 \mathrm{~F} \mathrm{~g}^{-1}$ even when the gravimetric current density was doubled as shown in Fig. 7(c). Fig. 7(d) displays the long cycling capability of the symmetric device which was conducted under a constant charging-discharging at $5 \mathrm{~A} \mathrm{~g}^{-1}$ for 10000 cycles. A $100 \%$ columbic efficiency and $100 \%$ capacitance retention were also recorded for this device, and obtained result compare to some similar materials earlier reported in the literature [28-31]. The result illustrates the stable nature of the material when adopting such neutral electrolyte in combination with the activated carbon nanostructured material from plant waste raw material, showing a high degree of device electrochemical stability and reversibility.

Voltage holding $(\mathrm{VH})$ tests is an interesting and comprehensive means of testing the device stability by subjecting the cell to a maximum operating potential over an extended period of time. Here, the device was subjected to a maximum potential of $1.8 \mathrm{~V}$ for $60 \mathrm{~h}$. Fig. $7(\mathrm{e})$ shows the $C_{\mathrm{s}}$ increase after each holding period of $10 \mathrm{~h}$. the $C_{\mathrm{s}}$ value increases markedly with 

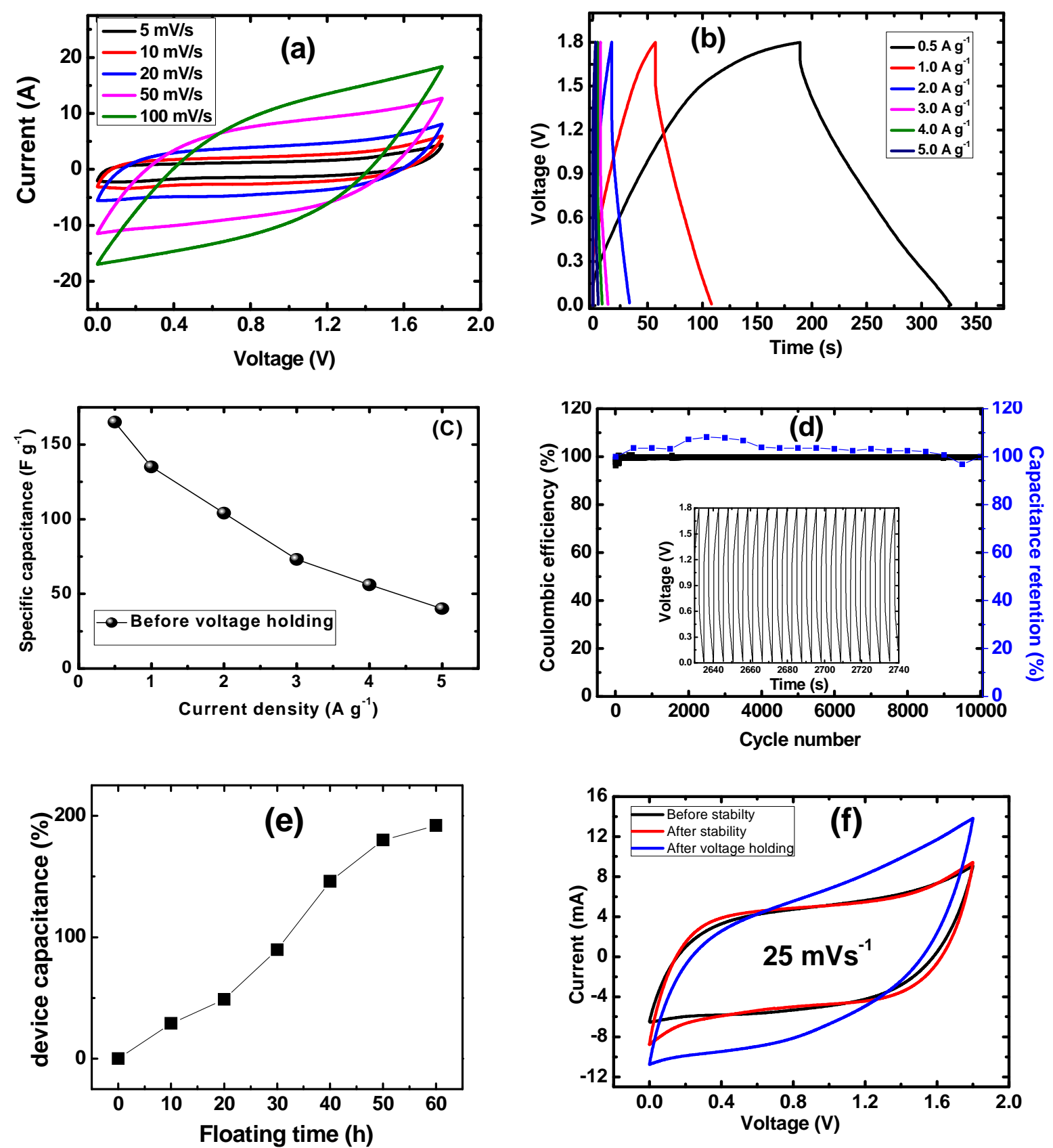

Fig. 7. $(a, b) C V$ and $C D$ plots of the activated banana peel sample (ABP900) at different scan rates and current densities respectively before voltage holding, (c) associated $\mathrm{C}_{\mathrm{s}}$ of the cell at different current densities, (d) columbic efficiency and capacitance retention as a function of cycle number at $5 \mathrm{~A} \mathrm{~g}^{-1}$, (e) recorded specific capacitance $\left(C_{s}\right)$ as a function of floating time showing increasing $\mathrm{C}_{\mathrm{s}}{ }^{-}$ values at $1 \mathrm{~A} \mathrm{~g}^{-1}$ and (f) CV plot of activated banana peel sample at $25 \mathrm{mVs}^{-1}$ before stability, after stability and after voltage holding. 
increasing floating time. This is supported by the increase in discharge time with floating time shown in Fig. S1(c). This specific capacitance reached a plateau after $60 \mathrm{~h}$ of floating time, displaying a specific capacitance increase of $192 \%$. This could be due to the availability of more pores during the repeated voltage holding test. In other words, this occurrence is attributed to the exposure of initially dormant porous storage sites from the expansion of the ABP900 porous structure with extended device operation at high operating potentials leading to more accessible surface for adsorption of an ion from the electrolyte hence increasing the capacitance of the cell. Furthermore, this result also suggests the robustness of the electrode material, since the collapse of the structure would have reduced the specific capacitance. This improvement is also remarkable when the discharge times before and after $\mathrm{VH}$ are compared like in Fig S1(d). Longer discharge time is observed after VH as shown in Fig. S1 (d), implying more charge separation and better polarity of the electrode materials. This behaviour is confirmed for all gravimetric current densities as shown in Fig. S1(e). Higher $C_{\mathrm{s}}$ values are obtained after $\mathrm{VH}$ for all gravimetric currents with almost the same rate capability as before $\mathrm{VH}$, between 1 to $5 \mathrm{~A} \mathrm{~g}^{-1}$. Fig. 7(f) compares the CV curves before and after cycling and floating test. No real change in CV curve is noticed before and after cycling, confirming the $100 \%$ capacitance retention observed up to 10000 cycles. The change in the CV is more visible after $\mathrm{VH}$. The higher surface under the CV curve is noticed when compared to that before $\mathrm{VH}$. This suggests more charge separation, confirming the increase in specific capacitance after VH shown in Fig. S1(f).

The calculation of the electrochemical surface area was adopted here to strengthen the novelty of this work. Trasatti et al. [32], reported that the surface area of a porous carbon material, A, can be calculated using the following equations: 


$$
A=\frac{C_{T}}{C_{0}}
$$

Where $C_{0}$ is a reference value and $C_{T}$ represents the total interfacial capacitance, which is also the slope obtained by plotting the current response, at a fixed potential, as a function of the scan rate. Before and after voltage holding, the total interfacial capacitances obtained were 0.14 and $0.22 \mathrm{~F}$, respectively. Since the value of $\mathrm{C}_{0}$ is not known and should be the same for the material before and after voltage holding, we resolve to the calculation of the ratio, $\alpha$, of the surface area after voltage holding to the surface area before voltage holding. Here, $\alpha=1.57$, implying that the electrochemical surface area increases by more than half its initial value after voltage holding. This is in a very good argument with the accessibility of hidden pores after voltage holding experiment.

To further investigate the electrical properties of the cell, EIS was performed before and after the different aforementioned tests. Fig. 8(a) shows the Nyquist plot from the EIS analysis of the device before and after cycling and voltage holding. The values of the solution resistance $\left(R_{\mathrm{s}}\right)$ and charge-transfer resistance $\left(R_{\mathrm{ct}}\right)$ were extrapolated from Fig. 8(a) and reported in table 2.

The solution resistance reveals the contribution of the intrinsic resistance of the material, current collector and ionic resistance of the electrolyte while the charge transfer resistance is linked to the ease of charge movement within the electrolyte $[16,17]$. Consequently, the reduction in the charge transfer resistance value after the voltage holding translates to an increase in cell capacitance.

However, the Nyquist plot after voltage holding shows a pronounced deviation from the vertical line in the low-frequency region. This hints at an increased leakage current from the 

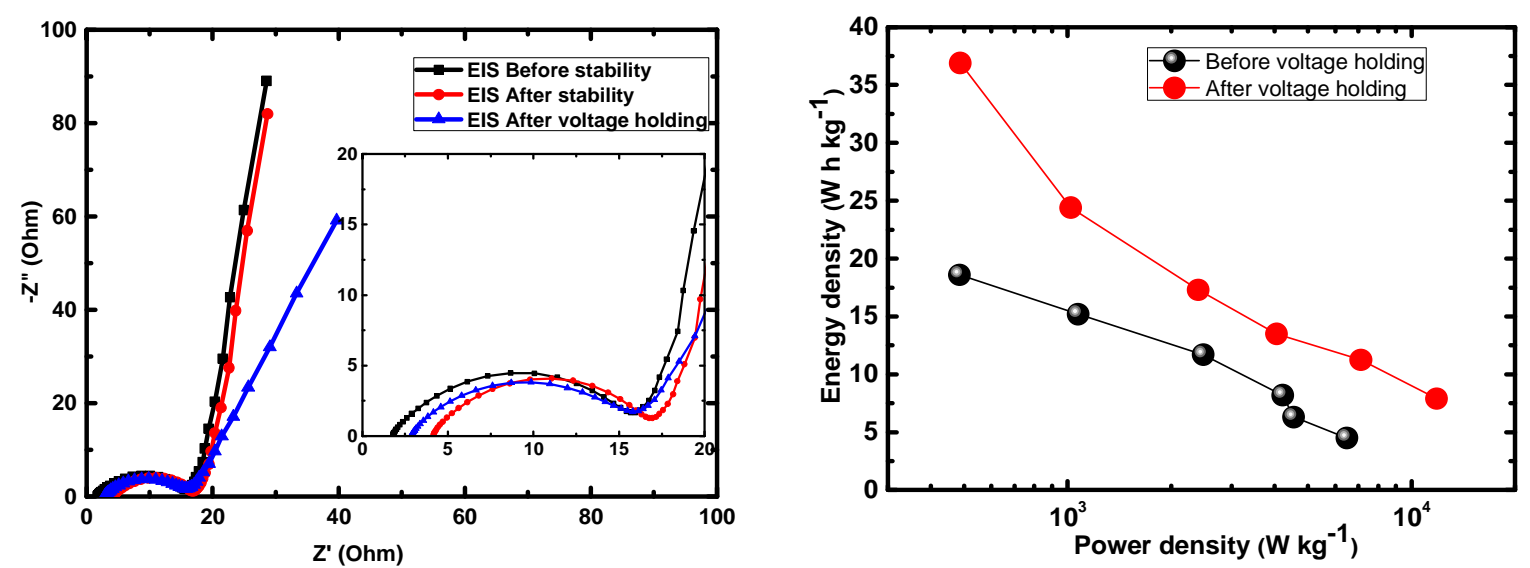

Fig. 8. (a) Nyquist plot for $A B P 900$ cell in $\mathrm{NaNO}_{3}$ (b) Ragone plot before and after voltage holding. 
Table 2: Summary of electrode properties from the EIS analysis of the symmetric device

\begin{tabular}{ccc}
\hline Device parameters & $\mathbf{R}_{\mathbf{s}}$ & $\mathbf{R}_{\mathrm{ct}}$ \\
\hline Before stability & 2.01 & 15.00 \\
After stability & 4.13 & 16.00 \\
After voltage holding & 3.00 & 14.80 \\
\hline
\end{tabular}


device. Yet, the diffusion length is shorter after voltage holding, showing improved device performance.

Thus, overall the reduction of diffusion length might play a bigger role in the device performance since an increase in the $C_{s}$ value was observed after $\mathrm{VH}$. Fig. $8(\mathrm{~b})$ shows the Ragone plot which emphasizes the energy-power characteristic of the device. An energy and power density values of $18.6 \mathrm{Wh} \mathrm{kg}^{-1}$ and $485 \mathrm{~W} \mathrm{~kg}^{-1}$, respectively, was initially recorded at current density $0.5 \mathrm{~A} \mathrm{~g}^{-1}$ for the device before voltage holding. The device later exhibited a $98 \%$ increase in the energy density to a value of $36.9 \mathrm{Wh} \mathrm{kg}^{-1}$ at the same initial gravimetric current density of $0.5 \mathrm{~A} \mathrm{~g}^{-1}$ after being subjected to a voltage holding for up to 60 hours in a maximum operating potential of $1.8 \mathrm{~V}$. This improvement still remains at $75 \%$ at the highest current density. This is a staggering improvement for supercapacitor research as the main aim is to improve their energy density without compromising on the power density. This has been achieved in this regard as seen in Fig. 8(b). Table 3 displays the comparison of the electrochemical properties of different biomass-derived activated carbon materials used as electrodes for supercapacitors. The present study shows an improvement over some earlier works done and is comparable to previously studied materials which have been reported.

\section{Conclusions}

Nanostructured activated carbon materials were prepared from low-value banana waste peels via an activation/carbonization technique at a different temperature range $\left(750-950{ }^{\circ} \mathrm{C}\right)$. The physico-chemical characterization of those samples proved that the carbon material prepared at $900{ }^{\circ} \mathrm{C}$ (ABP900) possessed the most promising properties suitable for the design of high- 
Table 3: Comparison of biomass carbon derived electrodes with results from present study

\begin{tabular}{|c|c|c|c|c|c|c|c|}
\hline $\begin{array}{l}\text { Source of } \\
\text { electrode } \\
\text { materials }\end{array}$ & $\begin{array}{l}\text { Activation } \\
\text { agent }\end{array}$ & Electrolyte & $\begin{array}{l}\text { Potential } \\
\text { (V) }\end{array}$ & $\begin{array}{l}\text { Specific } \\
\text { capacitance } \\
\left(\mathrm{Fg}^{-1}\right)\end{array}$ & $\begin{array}{l}\text { Energy } \\
\text { density } \\
\left(\text { Whkg }^{-1}\right)\end{array}$ & $\begin{array}{l}\text { Power } \\
\text { density } \\
\left(\mathbf{W k g}^{-1}\right)\end{array}$ & Ref. \\
\hline Pine cone & $\mathrm{KOH}$ & $1 \mathrm{M} \mathrm{Na}_{2} \mathrm{SO}_{4}$ & 2 & 137 & 19 & 100 & (6) \\
\hline Rice husk & $\begin{array}{l}\mathrm{NaOH} \& \\
\mathrm{KOH}\end{array}$ & $3 \mathrm{M} \mathrm{KCl}$ & 0.6 & 210 & $\begin{array}{l}\text { not } \\
\text { supplied }\end{array}$ & not supplied & 21 \\
\hline $\begin{array}{l}\text { Banana } \\
\text { fibre }\end{array}$ & $\begin{array}{l}\mathrm{ZnCl}_{2} \& \\
\mathrm{KOH}\end{array}$ & $1 \mathrm{M} \mathrm{Na}_{2} \mathrm{SO}_{4}$ & 1 & 74 & $\begin{array}{l}\text { not } \\
\text { supplied }\end{array}$ & not supplied & 4 \\
\hline $\begin{array}{l}\text { Sugarcane } \\
\text { bagasse }\end{array}$ & $\mathrm{ZnCl}_{2}$ & $1 \mathrm{M} \mathrm{H}_{2} \mathrm{SO}_{4}$ & 1 & 300 & 10 & not supplied & 22 \\
\hline $\begin{array}{l}\text { Pamelo } \\
\text { peels }\end{array}$ & None & $1 \mathrm{M} \mathrm{NaNO}_{3}$ & 1.7 & 43.5 & 17.1 & 420 & 23 \\
\hline $\begin{array}{l}\text { Sunflower } \\
\text { seed shell }\end{array}$ & $\mathrm{KOH}$ & $3 \mathrm{M} \mathrm{KOH}$ & 0.9 & 311 & 4.8 & 240 & 24 \\
\hline $\begin{array}{l}\text { Corn stalk } \\
\text { core }\end{array}$ & $\mathrm{KOH}$ & $6 \mathrm{M} \mathrm{KOH}$ & 1 & 260 & $\begin{array}{l}\text { not } \\
\text { supplied }\end{array}$ & not supplied & 25 \\
\hline Soya & $\mathrm{NaOH}$ & $1 \mathrm{M} \mathrm{H}_{2} \mathrm{SO}_{4}$ & 1.5 & 193 & 24.3 & 750 & \\
\hline Corncob & $\mathrm{KOH}$ & $1 \mathrm{M} \mathrm{H}_{2} \mathrm{SO}_{4}$ & 1.2 & 164 & 25 & 174 & 27 \\
\hline Sago bark & None & $5 \mathrm{M} \mathrm{KOH}$ & 1 & 180 & 5 & 400 & \\
\hline $\begin{array}{l}\text { Lablab } \\
\text { purpureus } \\
\text { Seeds }\end{array}$ & None & $5 \mathrm{M} \mathrm{KOH}$ & 1.7 & 300 & 17.4 & not supplied & 29 \\
\hline $\begin{array}{l}\text { Bamboo } \\
\text { shoot }\end{array}$ & None & $6 \mathrm{M} \mathrm{KOH}$ & 1 & 412 & $\begin{array}{l}\text { Not } \\
\text { supplied }\end{array}$ & not supplied & \\
\hline $\begin{array}{l}\text { Shaddock } \\
\text { peel }\end{array}$ & None & $6 \mathrm{M} \mathrm{KOH}$ & 1 & 321.7 & 82.1 & 899 & 31 \\
\hline \multirow{2}{*}{$\begin{array}{l}\text { Banana } \\
\text { peels }\end{array}$} & $\mathrm{KOH}$ & $1 \mathrm{M} \mathrm{NaNO}_{3}$ & 1.8 & 165 & 18.6 & $485^{*}$ & \multirow[t]{2}{*}{ This work } \\
\hline & & & & 328 & 36.9 & $487^{* *}$ & \\
\hline
\end{tabular}

*values before voltage holding, **Values after voltage holding 
performance supercapacitor device electrodes. The as-prepared ABP900 was tested in three different neutral aqueous electrolytes with the $\mathrm{NaNO}_{3}$ electrolyte giving the best electrochemical response when tested in half-cell configuration.

In the two electrode measurement, the electrochemical results obtained after voltage holding tests suggests a new approach to improving a supercapacitor device performance through an improved energy storage and delivery. The reason for an improvement in the device could be due to strong solvation of $\mathrm{Na}^{+}$and $\mathrm{NO}_{3}{ }^{-}$and accessibility of electrolyte into initially inaccessible pores of the activated carbon electrode material due to extensive device testing.

The results obtained from this study, therefore, provides a new path and blueprint into designing much stable electrochemical capacitors using much environmentally synthesis routes and less toxic electrode and electrolyte material.

\section{Acknowledgements}

This research work is supported by the South African Research Chairs Initiative (SARChI) of the Department of Science and Technology, the National Research Foundation (NRF) of South Africa (Grant No. 61056). Any opinion, finding and conclusion or recommendation expressed in this material is that of the author(s) and the NRF does not accept any liability in this regard. 0 . Fasakin also gratefully acknowledges the University of Pretoria, South Africa for accessibility to their research facilities and Obafemi Awolowo University (OAU) Ile-Ife, Nigeria for the leave support. 


\section{REFERENCES}

1 B. E. Conway, Electrochemical Supercapacitors: Scientific Fundamental and TechnologicalApplications, Kluwer Academic/Plenum Publishers: New York (1999).

2 P. Simon and Y. Gogotsi, Materials for electrochemical capacitors,Nat. Mater. (2008) 7 845-854.

3 L. Qie, W. Chen, H. Xu, X. Xiong, Y. Jiang, F. Zou, X. Hu, Y. Xin, Z. Zhang and Y. Huang, Synthesis of functionalized 3D hierarchical porous carbon for high-performance supercapacitors, Energy Environ. Sci. (2013) 6 2497-2504.

4 V. Subramanian, C. Luo, A. M. Stephan, K.S. Nahm, S. Thomas and B. Wei, Supercapacitors from activated carbon derived from banana fibersJ. Phys. Chem. C (2007) 111, 7527-7531.

$5 \quad$ X. He, P. Ling, M. Yu, X. Wang, X. Zhang and M. Zheng,Rice husk-derived porous carbons with high capacitance by $\mathrm{ZnCl}_{2}$ activation for supercapacitors, Electrochim. Acta.(2013) 105 635-641.

6 A. Bello, N. Manyala, F. Barzegar, A. A. Khaleed, D. Y. Momodu and J. Dangbegnon, Renewable pine cone biomass derived carbon materials for supercapacitor application, RSC Adv. (2016) 6 1800-1809.

7 K. Fic, G. Lota, M. Meller and E. Frackowiak, Novel insight into neutral medium as electrolyte for high-voltage supercapacitors, Energy Environ. Sci.(2012) 5 5842-5850.

8 A. Bello, F. Barzegar, M.J. Madito, D.Y. Momodu, A.A. Khaleed, T.M. Masikhwa,J.K. Dangbegnon, N. Manyala,Stability studies of polypyrole- derived carbon based symmetric supercapacitor via potentiostatic floating test, Electrochim. Acta(2016) 213 107-114.

9 F. Barzegar, A. Bello, J.K. Dangbegnon, N. Manyala, X. Xia,Asymmetric Carbon Supercapacitor with Activated Expanded Graphite as Cathode and Pinecone Tree Activated Carbon as Anode Materials, Applied energy (2017) 105 4098-4103

10 S. K., Sze, N, Siddique, J. J. Sloan and R. Escribano, Raman spectroscopy characterization of carbonaceous aerosols, Atmos. Environ. (2001) 35 561-568.

11 B. Dippel, H. Jander and J.Heintzenberg, NIR FT Raman spectroscopic study of flame soot, Physical Chemistry Chemical Physics (1999) 4707-4712.

12 T. Jawhari, A. Roid and J. Casado, Raman spectroscopic characterization of some commercially available carbon black materials, Carbon (1995) 33, 1561-1565. 
13 A. G. Pandolfo and A. F. Hollen Kamp,Carbon properties and their role in supercapacitors, J. Power Sources (2006) 157 11-27.

14 C. Zhong, Y. Deng, W. Hu, J. Qiao, L. Zhang and J. Zhang, A review of electrolyte materials and compositions for electrochemical supercapacitors, Chem. Soc. Rev., (2015) 44 7484-7539.

15 A. Bello, F. Barzegar, A. A. Khaleed, D. Y. Momodu, T. M. Mashikwa, J. Dangbegnon and N. Manyala, Electrochemical performance of polypyrrole derived porous activated carbon-based symmetric supercapacitors in various electrolytes, RSC Adv.(2016) 6 68141-68149.

16 J. G. Speight, Lange's handbook of chemistry, MCGRAW-HILL, 16th edn (2005).

17 A. G. Volkov, S. Paula and D. W. Deamer, Two mechanisms of permeation of small neutral molecules and hydrated ions across phospholipid bilayers, Bioelectrochem. Bioenerg. (1997) 42 153-160.

18 E. R. Nightingale, Phenomenological Theory of Ion Solvation. Effective Radii of Hydrated lons, J. Phys. Chem. (1959) 63 1381-1387.

19 J. Luo, H.D. Jang and J. Huang, Effect of Sheet Morphology on the Scalability of Graphene-Based Ultracapacitors ACS nano. (2013) 7 1464-1471.

20 A. D. Jagadale, G. Guan, X. Li, X. Du, X. Ma, X. Hao, A. Abudula, Ultrathin nanoflakes of +cobalt-manganes layered double hydroxide with high reversibility for asymmetric supercapacitor, J. Power Sources (2016) 306 526-534.

21 Y. Guo, J.Qi, Y. Jiang, S. Yang, Z. Wang and H. Xu, Performance of electrical double layer capacitors with porous carbons derived from rice husk, Mater. Chem. Phys. (2003) 80 704-709.

22 T.E. Rufford, D. Hulicova-Jurcakova, K. Khosla, Z. Zhu and G. Q. Lu, Microstructure and electrochemical double-layer capacitance of carbon electrodes prepared by zinc chloride activation of sugar cane bagasse, J. Power Sources (2010) 195 912-918.

23 C. Peng, J. Lang, S. Xu and X. Wang, Oxygen-enriched activated carbons from pomelo peel in high energy density supercapacitors,RSC Adv.(2014) 4 54662-54667.

24 X. Li, W. Xing, S. Zhou, J. Zhou, F. Li, S. Z. Qiao and G. Q. Lu, Preparation of capacitor's electrode from sunflower seed shell, Bioresour. Technol. (2011) 102 1118-1123.

25 Y. Cao, K. Wang, X. Wang, Z. Gu, Q. Fan,W. Gibbons, J. D. Hoefelmeyer, P. R. Kharel, M. Shrestha, Hierarchical porous activated carbon for supercapacitor derived from 
corn stalk core by potassium hydroxide activation Electrochimica Acta (2016) 212 839847

26 M. Rana, K. Subramani, M. Sathish, U. K. Gautam, Soya derived heteroatom doped carbon as a promising platform for oxygen reduction, supercapacitor and $\mathrm{CO}_{2}$ capture, Carbon (2017) 114 679-689.

27 M. Karnan, K. Subramani, P.K. Srividhya, M. Sathish, Electrochemical Studies on Corncob Derived Activated Porous Carbon for Supercapacitors Application in Aqueous and Nonaqueous Electrolytes Electrochimica Acta (2017) 228 586-596.

28 G. Hegde, S. A. Abdul Manaf, A Kumar, G. A. M. Ali, K. F. Chong, Z. Ngaini, and K. V. Sharma, Biowaste Sago Bark Based Catalyst Free Carbon Nanospheres: Waste to Wealth Approach ACS Sustainable Chem. Eng. (2015) 3 2247-2253.

29 G. A. M. Ali, A. Divyashree, S. Supriya, K. F. Chong, A. S. Ethiraj, M. V. Reddy, H. Algarnif, and $\mathrm{G}$. Hegde, Carbon nanospheres derived from Lablab purpureus for high performance supercapacitor electrodes: a green approach, Dalton Trans. (2017) 46 14034-14044.

30 X. Chen, J. Zhang, B. Zhang, S. Dong, X. Guo, X. Mu, \& B. Fei, A novel hierarchical porous nitrogen-doped carbon derived from bamboo shoot for high performance supercapacitor, Scientific reports, (2017) 77362.

31 K. Xiao, L. X. Ding, H. Chen, S. Wang, X. Lu, \& H. Wang, Nitrogen-doped porous carbon derived from residuary shaddock peel: a promising and sustainable anode for high energy density asymmetric supercapacitors, Journal of Materials Chemistry A, (2016) 42 372-378.

32 S. Trasatti and O. A. Petrii, Real Surface Area Measurement in Electrochemistry, J. Electroanal. Chem., (1992) 321 353-376. 